\title{
Differences in Nominal Significance (DINS) Error leads to invalid conclusions: Letter regarding, "Diet enriched with fresh coconut decreases blood glucose levels and body weight in normal adults"
}

\footnotetext{
${ }^{1}$ The University of Sydney, Charles Perkins Centre and School of Pharmacy, Faculty of Medicine and Health, D17, Level 6, The Hub, Sydney, NSW, 2006, Australia, E-mail: cynthia.kroeger@sydney.edu.au

${ }^{2}$ Department of Epidemiology and Biostatistics, Indiana University School of Public Health-Bloomington, Bloomington, IN, United States of America, E-mail: cynthia.kroeger@sydney.edu.au

${ }^{3}$ Department of Applied Health Science, Indiana University School of Public Health-Bloomington, Bloomington, IN, United States of America
}

Keywords: DINS error, nutrition, obesity, research rigor, Type I error DOI: 10.1515/jcim-2018-0037

Received: March 21, 2018; Accepted: February 25, 2019

\begin{abstract}
Vijayakumar et. al. [1] conducted a parallel-arm, randomized, controlled trial to test the effects of fresh coconut versus groundnut and groundnut oil on differences in anthropometric and cardiometabolic outcomes. The parallel-arm, randomized, controlled design is well-suited to test for effects between groups, and the authors conducted between-group statistical tests (independent $t$ tests). The data reported in Table 2 indicate that no statistically significant differences were observed among the coconut or groundnut groups for any outcome measures. However, the authors concluded that, "Daily consumption of $100 \mathrm{~g}$ of fresh coconut ... is found to be beneficial in reducing body weight and blood glucose levels" and that "[r]esults of this study suggest that fresh coconut-added diet helps reduce blood glucose levels and body weight in normal healthy individuals." These conclusions are based on within-group analyses, which has been well-described in the literature as invalid for between-group comparisons and tests of treatment effects in randomized, controlled trials [2,3].

The error of drawing conclusions based on within-group analyses is known as the Differences in Nominal Significance (DINS) error [4]. DINS errors are common within nutrition and obesity research [5] and have led to the correction [6] or retraction [7] of other papers in the field. DINS errors can distort the scientific record by inflating Type I error rates from the expected 5\% (i.e., when alpha has been deemed 0.05 ) to rates as high as $50 \%$ when comparing two groups of equal sample sizes $[3,5,8]$.

Because the data refute the conclusions drawn by Vijayakumar et. al. as stated within the study abstract and full text, we believe the publication should be corrected or retracted. Such action is consistent with the Committee on Publication Ethics (COPE) guidelines [9]. A valid conclusion would communicate the non-significant results of the between-groups tests, consistent with the randomized design.
\end{abstract}

\section{Acknowledgments}

Supported in part by the National Institutes of Health, grants F32DK107157, R25DK099080, and R25HL124208. The content is solely the responsibility of the authors and does not necessarily represent the official views of the National Institutes of Health or any other organization.

Author contributions: All the authors have accepted responsibility for the entire content of this submitted manuscript and approved submission. 
Research funding: None declared.

Employment or leadership: None declared.

Honorarium: None declared.

Competing interests: The funding organization(s) played no role in the study design; in the collection, analysis, and interpretation of data; in the writing of the report; or in the decision to submit the report for publication.

\section{References}

[1] Vijayakumar V, Shankar NR, Mavathur R, Mooventhan A, Anju S, Manjunath NK. Diet enriched with fresh coconut decreases blood glucose levels and body weight in normal adults. J Complement Integr Med. 2018;15.

[2] Celman A, Stern H. The difference between "Significant" and "Not Significant" is not itself statistically significant. Am Statist. 2006;60:328-31.

[3] Bland JM, Altman DC. Comparisons against baseline within randomised groups are often used and can be highly misleading. Trials. 2011;12:264.

[4] Allison DB, Brown AW, Ceorge B], Kaiser KA. Reproducibility: A tragedy of errors. Nature. 2016;530:27-9.

[5] Ceorge B], Beasley TM, Brown AW, Dawson ], Dimova R, Divers ], et al. Common scientific and statistical errors in obesity research. Obesity (Silver Spring). 2016;24:781-90.

[6] Allison DB, Antoine LH, George B]. Incorrect statistical method in parallel-groups RCT led to unsubstantiated conclusions. Lipids Health Dis. 2016;15:77.

[7] Cassani RS, Fassini PG, Silvah ]H, Lima CM, Marchini JS. Retraction note: impact of weight loss diet associated with flaxseed on inflammatory markers in men with cardiovascular risk factors: a clinical study. Nutr ]. 2016;15:59.

[8] Bland JM, Altman DC. Best (but oft forgotten) practices: testing for treatment effects in randomized trials by separate analyses of changes from baseline in each group is a misleading approach. Am J Clin Nutr. 2015;102:991-4.

[9] Committee on publication ethics (COPE). Retraction Guidelines. Available at: https://publicationethics.org/files/retraction\%20guidelines.pdf. 